\title{
OPTICAL COHERENCE TOMOGRAPHY ASSESSMENT OF STRUCTURAL CHANGES IN THE OPTIC NERVE HEAD AND PERIPAPILLARY RETINA IN IDIOPATHIC INTRACRANIAL HYPERTENSION
}

\section{Corina I. MERTICARIU ${ }^{1,2} \bowtie$, Florian BALTA ${ }^{2,3}$, Andrei MERTICARIU ${ }^{2,3}$, Radu CIULUVICA ${ }^{4}$, Liliana VOINEA ${ }^{4}$}

1 „Victor Gomoiu“ Pediatric Hospital, Bucharest, Romania

${ }^{2}$ Retina Clinic, Bucharest, Romania

${ }^{3}$ Emergency Eye Hospital, Bucharest, Romania

${ }^{4}$ Department of Ophthalmology, University Emergency Hospital, Bucharest, Romania

\section{Abstract}

Introduction. Reliable detection of papilledema is essential for establishing the diagnosis of Idiopathic Intracranial Hypertension (IIH). The ophtalmoscopic fundus examination of the optic nerve head $(\mathrm{ONH})$ is a subjective measurement, limited by the examiner's experience, the patient's degree of collaboration and the optics of the ophthalmoscope, making it often unreliable in detecting early edema and in assessing initial improvements or worsening.

The objective of the study was to assess the role of optical coherence tomography (OCT) in diagnosing and monitoring papilledema in IIH.

Materials and methods. The study period consisted of 3 years (October 2014- October 2017) in which we evaluated how OCT parameters correlated with the clinical grading of the optic nerve head $(\mathrm{ONH})$ edema according to the Frisén's scale. We included 11 patients ( 6 adults and 5 adolescents aged 15 years and above) with recently diagnosed IIH in the University

\section{RÉsumé}

Evaluation des modifications structurelles de la tête du nerf optique et de la rétine péri-papillaire par tomographie en cohérence optique dans l'hypertension intracrânienne idiopathique

Introduction. Une détection fiable de l'œè̀me papillaire est une considération essentielle pour établir le diagnostic de l'hypertension intracrânienne idiopathique (HTIC), mais l'examen ophtalmoscopique du fond d'œil de la tête du nerf optique (ONH) est une mesure subjective limitée par l'expérience de l'examinateur, le degré de la collaboration et l'optique de l'ophtalmoscope, le rendant souvent peu fiable pour détecter un odème précoce et pour évaluer les améliorations ou aggravations initiales.

Le but de l'étude était d'évaluer le rôle de la tomographie par cohérence optique (OCT) dans le diagnostic et la surveillance de l'œdème papillaire produit par IIH. 
Emergency Eye Hospital and 'Prof. Dr. Al. Obregia Psychiatry Hospital, Bucharest, Romania. Patients underwent clinical evaluation and OCT examination in the Retina Clinic, Bucharest, Romania. The measurements were compared to a group of 13 subjects with demographic characteristics similar to the study lot, without IIH (7 adults and 6 adolescents over 15 years).

Results. The average retinal nerve fiber layer (RNFL) thickness in the study lot was $165.8 \mu \mathrm{m},(95 \% \mathrm{CI}$ $\pm 33 \mu \mathrm{m})$ compared to $116 \mu \mathrm{m}(95 \% \mathrm{CI}, \pm 4.3 \mu \mathrm{m})$ in the control group, $\mathrm{P}=0.001$. We demonstrated a significant difference between the average RNFL thickness correlated to papilledema severity $(\mathrm{r}=0.967, \mathrm{~N}=22$, $\mathrm{P}=0.001)$, with an average value of $117 \mu \mathrm{m}(95 \% \mathrm{CI}$, $\pm 16 \mu \mathrm{m})$ in case of mild edema, $165 \mu \mathrm{m}(95 \% \mathrm{CI}$, $\pm 89 \mu \mathrm{m})$, in moderate cases and $269 \mu \mathrm{m}(95 \% \mathrm{CI}, \pm 31$ $\mu \mathrm{m})$ in severe cases.

Conclusions. Fundal photographs and optical coherence tomography can be used with clinical assessment and other visual tests for the diagnosis of papilledema. Frisén grade determined by direct fundus examination was significantly correlated with OCT parameters reflecting optic nerve head edema. Following the peripapillary RNFL thickness over different check-ups provides a quantitative and sensitive measurement of changes in the papilledema.

Keywords: idiopathic intracranial hypertension, optical coherence tomography, papilledema, retinal nerve fiber layer thickness.

\section{Abbreviations:}

IIH- Idiopathic Intracranial Hypertension

OCT- Optical Coherence Tomography

ONH- Optic Nerve Head

RNFL- Retinal Nerve Fiber Layer

SS-OCT-Swept Source OCT

\section{INTRODUCTION}

Idiopathic Intracranial Hypertension (IIH) is characterized by elevated intracranial pressure in the setting of normal cerebrospinal fluid (CSF) composition, without evidence of a mass lesion or sinus thrombosis on neuroimaging ${ }^{1-3}$. It was traditionally considered a "benign" disease of young overweight women. As the vast majority of patients with IIH complain of impairing headaches, medical attitude towards IIH varies ${ }^{4}$.
Matériaux et méthodes. La période d'étude comprenait 3 années (octobre 2014 à octobre 2017) au cours desquelles nous avons évalué la corrélation entre les paramètres de l'OCT et la classification clinique de l'œdème de la tête du nerf optique $(\mathrm{ONH})$ selon l'échelle de Frisén. Nous avons inclus $11 \mathrm{pa}-$ tients ( 6 adultes et 5 adolescents âgés de 15 ans et plus) récemment diagnostiqués IIH à l'Hôpital des Urgences Ophtalmologique et à l'l'Hôpital «Prof. Dr. Al. Obregia», Hôpital psychiatrique de Bucarest, Roumanie. Les patients ont subi une évaluation clinique et un examen OCT à la clinique Rétine, Bucarest, Roumanie. Les mesures ont été comparées à un groupe de 13 sujets présentant des caractéristiques démographiques similaires à celles du lot à l'étude, sans IIH ( 7 adultes et 6 adolescents de plus de 15 ans). Résultats. L'épaisseur moyenne de la couche de fibres nerveuses rétiniennes (RNFL) dans le lot à l'étude était de 165,8 $\mu \mathrm{m}$ (IC 95\% $\pm 33 \mu \mathrm{m}$ ), contre $116 \mu \mathrm{m}(\mathrm{IC} 95 \% \pm 4,3 \mu \mathrm{m})$ dans le groupe témoin, $\mathrm{P}=0,001$. Nous avons également mis en évidence une différence significative entre l'épaisseur moyenne de RNFL corrélée à la sévérité de l'œdème papillaire $(\mathrm{r}=$ $0,967, \mathrm{~N}=22, \mathrm{P}=0,001)$ et une valeur moyenne de $117 \mu \mathrm{m}$ (IC 95\%, $\pm 16 \mu \mathrm{m})$ en cas d'œè̀me léger, 165 $\mu \mathrm{m}(95 \% \mathrm{CI}, \pm 89 \mu \mathrm{m})$, dans les cas modérés et 269 $\mu \mathrm{m}(95 \% \mathrm{IC}, \pm 31 \mu \mathrm{m})$ dans les cas graves.

Conclusions. Les photographies de fond et la tomographie par cohérence optique peuvent être utilisées avec une évaluation clinique et d'autres tests visuels pour le diagnostic d'oedème papillaire. Le degré de l'œedème de la tête du nerf optique $(\mathrm{ONH})$ selon l'échelle de Frisén déterminée par l'examen direct du fond d'œil était corrélé de manière significative avec les paramètres d'OCT reflétant un œè̀me de la tête du nerf optique. Le suivi de l'épaisseur du RNFL péri-papillaire au cours de différents examens fournit une mesure quantitative et sensible des changements dans l'œdème papillaire.

Mots-clés: hypertension intracrânienne idiopathique, tomographie par cohérence optique, œdème papillaire, épaisseur de la couche de fibres nerveuses rétiniennes.

Application of diagnostic principles, such as the modified Dandy criteria and the 2013 criteria proposed by Friedman et al, assist in making the positive diagnosis in most cases ${ }^{5,6}$. However, an aspect of IIH that constitutes a crucial consideration in establishing the diagnosis is the reliable detection of papilledema, as papilledema associated with IIH may result in irreversible, progressive visual loss ${ }^{7-9}$.

Examination of the ocular fundus is a particular point of the ophthalmological examination that 
many emergency department physicians, neurologists and residents in training are unfamiliar with and is consequently either poorly performed or completely ignored ${ }^{10}$. Furthermore, there are limitations to the ophthalmoscopic fundus examination, especially when performed in uncooperative patients or in nonmydriatic pupils, best exemplified in the setting of evaluating young patients for possible $\mathrm{IIH}^{11}$.

Optical coherence ocular tomography is a non-invasive imaging technique that uses near infrared light to scan the ocular fundus. It provides high resolution cross section images of the peripapillary retina and optic nerve head, allowing exact measurement of morphological changes that may decrease the diagnostic uncertainty of papilledema ${ }^{12-14}$.

\section{Material and methods}

We performed a prospective study to test whether the introduction of swept source ocular coherence tomography (SS-OCT) has the potential to reduce interobserver variability and add accuracy to the diagnostic algorithm of IIH. Our hypothesis was that the new highly sensitive 3D- segmentation algorithm of the SS-OCT could reliably detect and measure the morphological changes in the optic nerve head and adjacent retina in the setting of IIH.

The study spanned over a 3-year period (October 2014-October 2017) and included eleven patients. Six of the patients were adults (over 18 years) and five were adolescents (ages 15 years to 18 years) diagnosed and treated in the University Emergency Eye Hospital and 'Prof. Dr. Al. Obregia" Psychiatry Hospital, Bucharest, Romania. IIH is a disease that typically affects post-pubertal overweight women of childbearing age. However, cases have been described in children, as there is growing obesity among young children and adolescents. We included five adolescents over 15 years because after the onset of puberty IIH is considered to have the same demographic characteristics as in adults. The study met the requirements of the Ethical Committee and all patients signed a consent form.

We initially selected the medical records according to the International Classification of Diseases (ICD) code used for benign intracranial hypertension, G93.2. Patients that had other associated neurological or ophthalmological conditions, previous eye surgery or secondary causes of IIH were excluded from the study. The final study group consisted of eleven patients (22 eyes) that were enrolled based on the modified Friedman criteria for positive diagnosis of IIH:

1. Papilledema.

2. Normal neurological examination except for cranial nerve abnormalities.
3. Neuroimaging: Normal brain parenchyma without hydrocephalus, mass or structural lesion and no abnormal meningeal enhancement or venous sinus thrombosis on MRI and MR venography; if MRI is unavailable or contraindicated, contrast enhanced CT may be used.

4. Normal CSF composition.

5. Elevated CSF opening pressure $\left(\geq 25 \mathrm{~cm} \mathrm{H}_{2} \mathrm{O}\right)$ in a properly performed lumbar puncture ${ }^{5}$.

A diagnosis of IIH is definite in patients fulfilling criteria 1 to 5 ; the diagnosis is probable if the first four are met, but the CSF pressure is lower than specified. All patients had a neuro-ophthalmological evaluation that included ocular motility, pupillary reactivity and slit lamp examination of the fundus in the Retina Clinic, Bucharest, Romania. Visual acuity was tested using a Snellen chart and color vision with Ishihara color plates. Automated perimetry was performed using a Compass fundus perimeter, which is a scanning ophthalmoscope combined with an automatic perimeter, that allows the acquisition of confocal images of the retina, simultaneously to the measurement of retinal threshold sensitivity and the analysis of fixation, enabling a correlation to be made between visual function and retinal structure.

Ocular coherence tomography was performed using the swept source OCT, DRI OCT- Triton (Topcon, Tokyo, Japan). The SS-OCT uses a tunable laser with a central wavelength of $1050 \mathrm{~nm}$ and a sweeping range of $100 \mathrm{~nm}$ that captures 100000 A-scans per second, which is a step forward from the Spectral Domain OCT (SD-OCT) that uses an SLD with a fixed wavelength of $840 \mathrm{~nm}$ and allows only 50000 A scans/second. Previous studies demonstrated that measurements of the retinal nerve fiber layer (RNFL) and ganglion cell-inner plexiform layer (GCL-IPL) using a 2-D segmentation algorithm is prone to errors especially in the case of full-blown edema. Therefore, we used the 3-D segmentation algorithm, with higher accuracy and reproducibility in evaluating the optic nerve head $(\mathrm{ONH})$ and peripapillary retinal nerve fiber RNFL thickness in all four quadrants and their average sum.

To indicate the quality of the results the DRIOCT uses a colored scale that ranges $0 \mathrm{~dB}$ to $100 \mathrm{~dB}$ to indicate signal strength. According to the manufacturer's recommendations, only scans with signal strength over $70 \mathrm{~dB}$, with accurate identification of the retinal fiber layer and inner plexiform layer borders and without movement artifacts were used. To ensure the data were reproducible, each eye was scanned twice and the best scan was selected.

Because our study included adolescents and the software has a normative database that includes only adults with ages 20 to 80 years, the results were 
compared to scans obtained from a normal group that consisted of 13 adults and children with similar age and sex distribution to the study group.

All data were summarized and displayed as mean, standard deviation (SD) and the $95 \%$ confidence interval (CI) of the mean. Student t-test was used for comparison of data with equal variance and comparison between groups and Pearson's Correlation Coefficients were used to assess the relation between structural and clinical parameters. Statistical significance was defined as $\mathrm{P}$ value $<0.01$ (two tailed). The SPSS statistical software was used to perform the statistical evaluation (SSPS Inc., Chicago, IL, USA).

\section{Results}

The mean age of subjects in the study group was 23.5 years (min 15 years, max 47 years) with a sex ratio of ten women to one man. The control group consisted of eleven women and two men and the mean age was 23.3 years (min 15 years, max 49 years). The mean body mass index in the study lot was $30.77 \mathrm{~kg} /$ $\mathrm{m}^{2}\left(\min 20.4 \mathrm{~kg} / \mathrm{m}^{2}\right.$, max $\left.59.2 \mathrm{~kg} / \mathrm{m}^{2}\right)$ and $30.13 \mathrm{~kg} /$ $\mathrm{m}^{2}$ in the control group $\left(\min 20 \mathrm{~kg} / \mathrm{m}^{2}\right.$, max 53.19 $\mathrm{kg} / \mathrm{m}^{2}$ ).

Patients in the study lot underwent lumbar puncture, with a mean opening pressure of $32 \mathrm{cmH}_{2} \mathrm{O}$ (range 26-43 $\mathrm{cmH}_{2} \mathrm{O}$ ). Headache was the most frequently reported symptom in the IIH group, as all patients complained of either migraines or cephalalgia. We noted no difference regarding the type, distribution, frequency, intensity, and duration of headache or response to painkillers. Seven subjects reported transient visual obscurations; nine patients had pulsatile tinnitus and three had associated double vision. Ten eyes had a mildly reduced best-corrected visual acuity (BCVA) (Snellen Chart 1-0,9), six eyes had a moderately reduced BCVA (Snellen chart 0,8-0,5) and six eyes had a BCVA less than 0,1. Enlargement of the blind spot was the most frequent visual field defect, present in half of the study eyes followed by concentric narrowing in four eyes.

The protocol used for retinal nerve fiber layer (RNFL) thickness assessment was the 3-D protocol in which a $3.46-\mathrm{mm}$ circular scan was placed around the optic disc to obtain peripapillary RNFL thickness data, generating a $6 \times 6 \mathrm{~mm}^{2}$ cube of information. Parameters automatically calculated by the DRI-OCT software and evaluated in this study included average thickness $\left(360^{\circ}\right.$ measure), temporal quadrant thickness, superior quadrant thickness, nasal quadrant thickness, inferior quadrant thickness, disc area, rim area, C/D ratio and cup volume of each eye.

As expected, study eyes had significant thickening of the peripapillary nerve fiber layer. Average RNFL was significantly different between the study lot and the control lot. The average RNFL in the study lot was $165.8 \mu \mathrm{m},(95 \% \mathrm{CI} \pm 33 \mu \mathrm{m})$ versus $116 \mu \mathrm{m}(95 \% \mathrm{CI}, \pm 4.3 \mu \mathrm{m})$ in the control group, $\mathrm{P}=0.001$. All parameters reflecting $\mathrm{ONH}$ edema and peripapillary retinal thickening were highly correlated. The mean disc area was significantly larger in the study lot compared to the control group (mean $3.53 \mathrm{~mm}^{2} \pm 0.98 \mathrm{~mm}^{2}$ versus $1.62 \mathrm{~mm}^{2} \pm 0.15 \mathrm{~mm}^{2}$, $\mathrm{P}=0.001)$.

The mean C/D linear ratio was significantly lower in the study lot compared to the control group 0.065 (95\% CI, \pm 0.04 ) versus 0.41 (95CI, \pm 0.09 ), $\mathrm{P}=0.001$ ). The mean rim area was significantly larger in the study lot $2.41 \mathrm{~mm}^{2}\left(95 \% \mathrm{CI}, \pm 0.81 \mathrm{~mm}^{2}\right)$ versus $1.43 \mathrm{~mm}^{2}\left(95 \% \mathrm{CI}, \pm 0.25 \mathrm{~mm}^{2}\right), \mathrm{P}=0.001$. RNFL thickness in each quadrant was significantly different between the two lots (Table 1).

Table 1 summarizes the mean retinal nerve fiber layer (RNFL) thickness in the study lot and control lot measurements and the statistical significance of the differences between the means. The results are displayed for each peripapillary quadrant.

We used the modified Frisen staging system used in the IIHTT (Idiopathic Intracranial Hypertension Treatment Trial) to assess ONH edema. Early on, there is loss of translucency along the vertical poles and nasal margins of the optic disc, producing a "C"-shaped whitish halo at the disc margin (grade I) that spreads temporally (grade II). Continued thickening of the RNFL progressively obscures some of the blood vessels at the disc margin (grade III), then obscures vessels on the optic disc itself (grade IV), and eventually obscures all of the vessels on the disc (grade V). The mean grade of papilledema in our study was 3 . One patient already had optic atrophy ${ }^{15}$.

Table 1. Differences in RNFL thickness in each quadrant in the study lot and control group.

\begin{tabular}{cccc}
\hline RNFL by quadrant & Study lot $($ mean \pm SD) & Control lot $($ mean \pm SD) & Statistical significance \\
\hline Nasal quadrant & $158.7 \mu \mathrm{m} \pm 48 \mu \mathrm{m}$ & $83.8 \mu \mathrm{m} \pm 6 \mu \mathrm{m}$ & $\mathrm{P}=0,01$ \\
\hline Superior quadrant & $182.2 \mu \mathrm{m} \pm 40 \mu \mathrm{m}$ & $139 \mu \mathrm{m} \pm 6.1 \mu \mathrm{m}$ & $\mathrm{P}=0,03$ \\
\hline Temporal quadrant & $175.4 \mu \mathrm{m} \pm 81 \mu \mathrm{m}$ & $84.3 \mu \mathrm{m} \pm 6.6 \mu \mathrm{m}$ & $\mathrm{P}=0,01$ \\
\hline Inferior quadrant & $186.3 \mu \mathrm{m} \pm 41 \mu \mathrm{m}$ & $146.7 \mu \mathrm{m} \pm 6 \mu \mathrm{m}$ & $\mathrm{P}=0,03$ \\
\hline
\end{tabular}

Source: Data from the first author's personal archive 


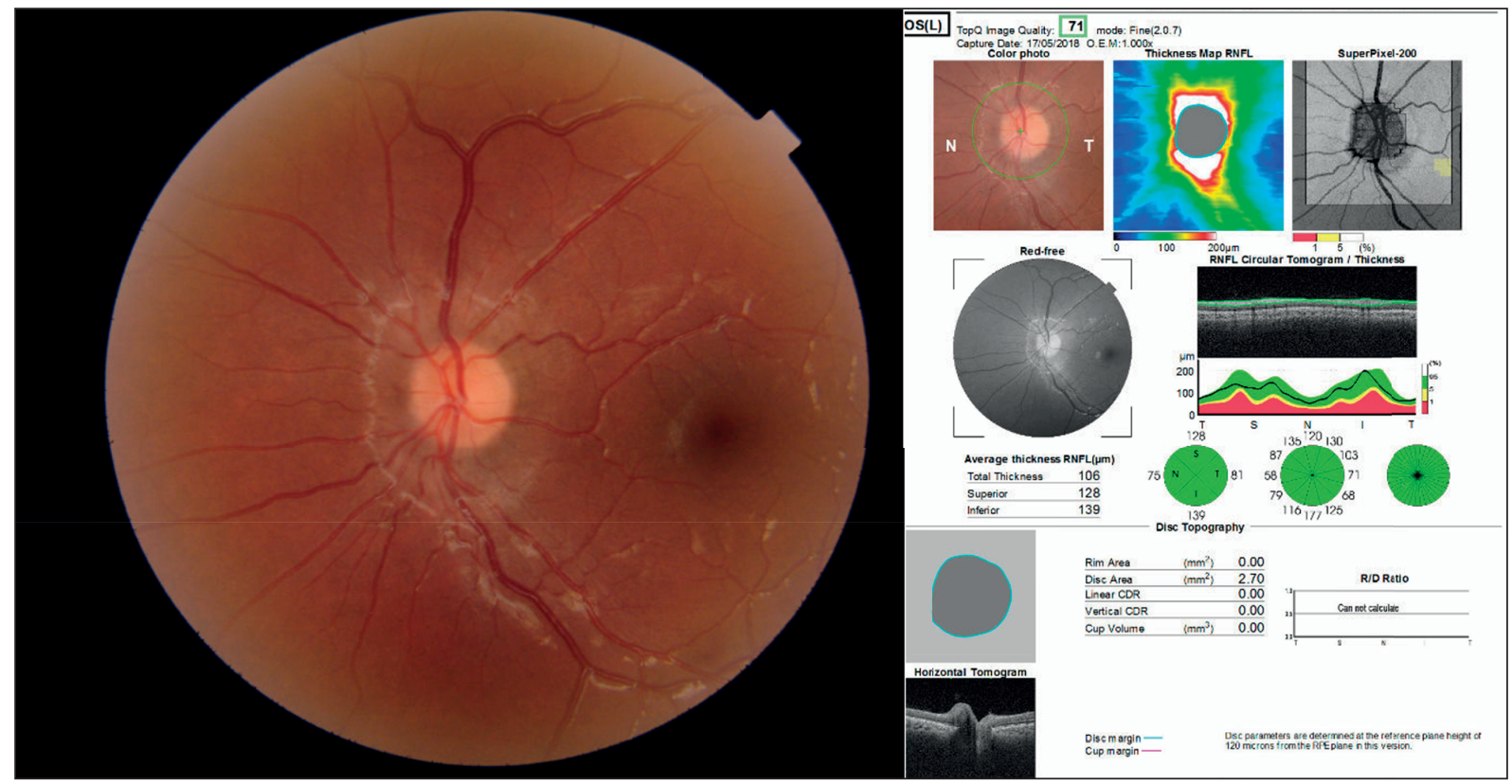

Fig. 1. Fundal photograph and corresponding output generated by the SS- OCT in a normal ONH without edema. Source: Images from the author's personal archive. SS- OCT- swept source OCT, ONH- optic nerve head.
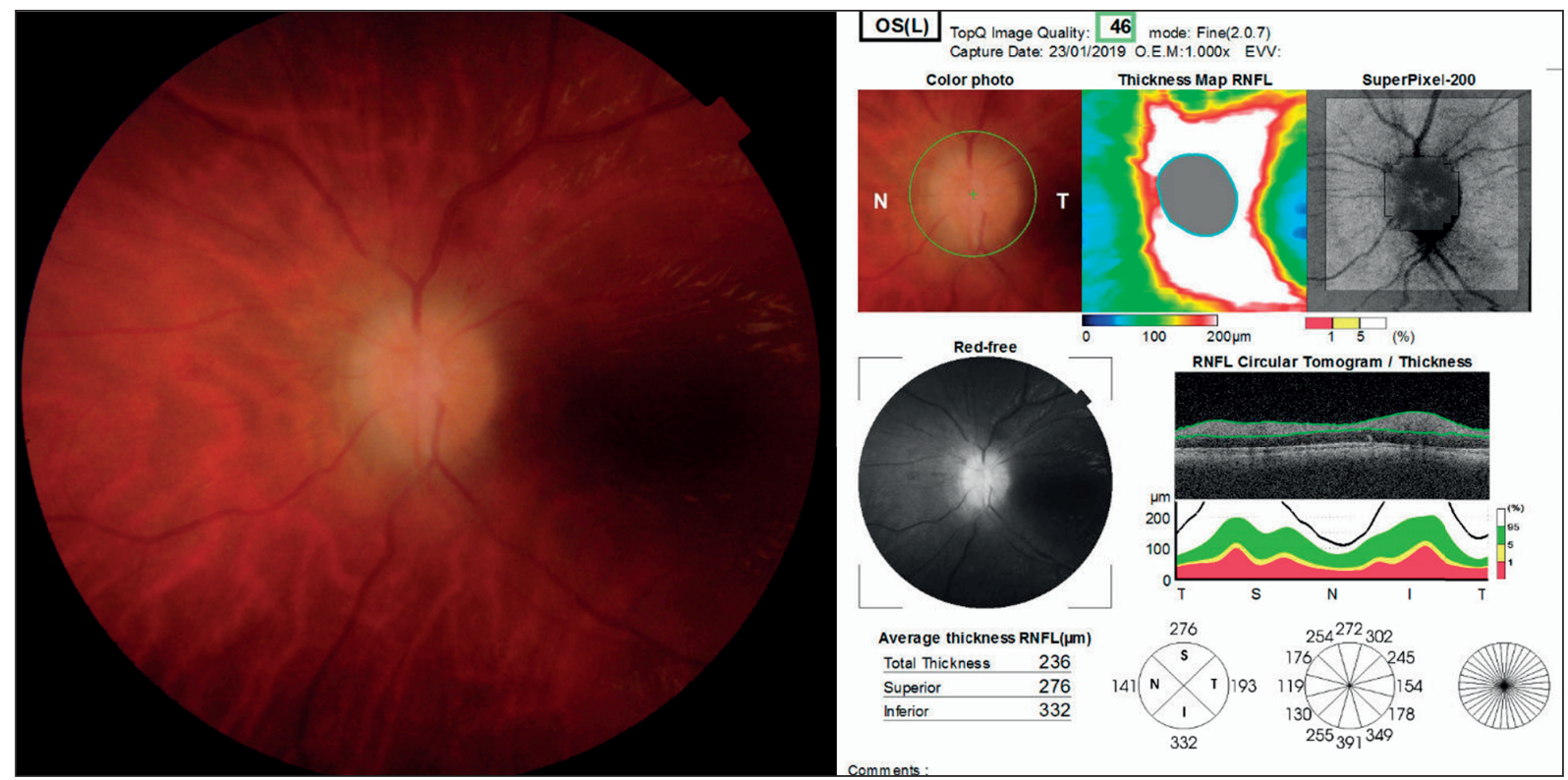

Fig. 2. Fundal photograph of grade 4 papilledema

Source: Images from the first author's personal archive. Fundal photograph of grade 4 papilledema (moderate to severe),

with an elevated disc and $360^{\circ}$ peripapillary halo, with corresponding optical coherence tomography showing

an increase in retinal nerve fiber layer thickness in a patient with IIH. IIH - Idiopathic Intracranial Hypertension.

All eyes were divided into three groups based on optic disc appearance 'Normal optic disc/mild elevation' group (6 eyes) was defined as sharp optic disc margins within at least three quadrants and a maximum of one quadrant with a mildly elevated optic disc and comprised Frisén grades 0,1,2 papilledema (Fig. 1). 'Full-blown papilledema' group (12 eyes) included Frisén grade 4 and 5 papilledema was defined by at least three quadrants with optic disc swelling and one quadrant with at least mild optic disc elevation. 'Moderate elevation' group (4 eyes) was defined as Frisén grade 3 papilledema (Fig. 2).

We found no significant correlation neither between initial visual acuity and average RNFL $(\mathrm{r}=0.028, \mathrm{n}=22, \mathrm{p}=0.89)$ nor between MD and average RNFL ( $r=0.03, n=22, P=0.086)$.

However, the Pearson's Correlation Coefficients demonstrated a strong positive correlation between 

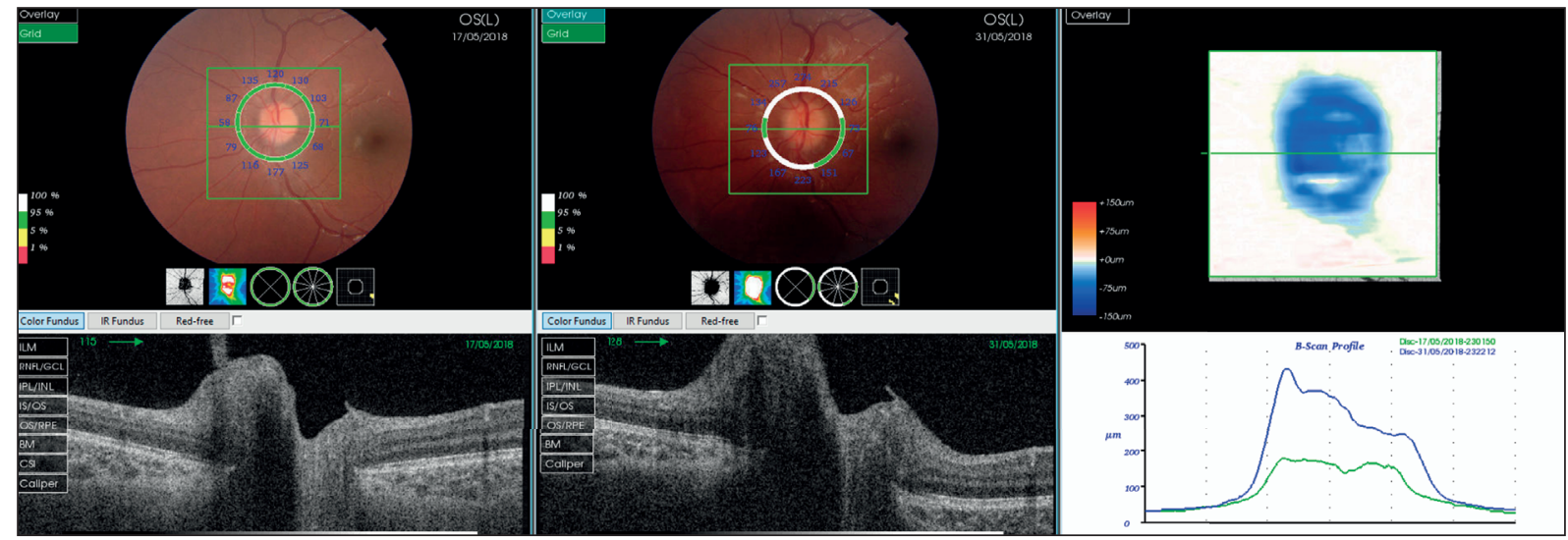

Fig. 3. Optical Coherence Tomography and fundus photo of resolution of papilledema. Source: Images from the first author's personal archive. Comparison between Fundus photo of the ONH edema and OCT measurements taken 2 weeks apart. The thickness graph provides a useful tool to monitor early response to treatment in a relapsing patient with $\mathrm{IIH}$, undetectable through fundus examination alone.

the mean average RNFL thickness and mean Frisén grade papilledema $(r=0.967, \mathrm{~N}=22, \mathrm{P}=0.001)$. For the normal/mild elevation group average RNFL thickness was $117 \mu \mathrm{m}(95 \% \mathrm{CI}, \pm 16 \mu \mathrm{m})$, for the moderate elevation group $165 \mu \mathrm{m}(95 \% \mathrm{CI}, \pm 89 \mu \mathrm{m})$, and for the full-blown papilledema group $269 \mu \mathrm{m}(95 \% \mathrm{CI}, \pm 31$ $\mu \mathrm{m})$. We also found a moderate correlation between average RNFL and lumbar opening pressure, but it did not reach statistical significance $(r=0.39, n=22, P=0.06)$.

As there is significant variability even among experts in grading papilledema based on the Frisén scale and the OCT allows comparison of measurements of the same patient over time, the peripapillary RNFL is easier to follow objectively for changes, especially when different care providers see the patient (Fig. 3).

Over follow-up, average RNFL thickness was correlated with the ophthalmoscopic degree of papilledema, making it a reproducible tool in monitoring disease progression and response to therapy.

\section{Conclusions}

Idiopathic Intracranial Hypertension is a disease of unknown etiology in which visual loss is the only irreversible comorbidity. Almost 10\% of patients end up legally blind. ${ }^{16,17}$ Although it is the only irreversible damage of the disease, visual loss in IIH can be caused by both outer retinal changes and optic neuropathy. Distinguishing outer retinal changes from optic neuropathy as the cause of decreased visual acuity is important, because outer retinal changes in the macula affecting visual acuity may be largely reversible, whereas optic neuropathy may require more aggressive management, to prevent further vision loss and irreversible blindness ${ }^{6}$.

The development of tools for the evaluation of uncooperative patients with IIH is particularly relevant as many patients may not be able to comply with the detailed clinical evaluation used in adults for the treatment and management of this disease. ${ }^{9}$ In our study OCT parameters proved to be a reliable tool in the diagnosis of papilledema. However, the significance of our results is limited, due to the small number of study eyes, although our results are statistically significant.

Chronically elevated ICP leads to increased pressure around the distal optic nerve, consequently decreasing axoplasmic nerve flow ${ }^{4}$. The axoplasmic stasis leads to intraaxonal edema, followed by compression of the venules, ischemia and impaired visual function $^{18}$. Central field visual acuity can be normal until late in the course of the disease. Visual field changes are a more sensitive parameter in detecting visual loss associated with IIH, however, it depends largely on the patients collaboration and cannot be used in young children ${ }^{19,20}$. Therefore, identifying structural changes in the $\mathrm{OHH}$ is important in assessing the response to treatment or worsening of the disease. In our study group, OCT was useful in identifying subclinical changes in the $\mathrm{ONH}$ and peripapillary retina, before they were visible by slit-lamp examination.

Assessing ONH edema by direct fundus ophthalmosocopy depends, on the one hand, on the examiner's expertise, and on the other, on the patient's degree of collaboration, making it often an impractical examination particularly. Moreover, grading papilledema according to the Frisén scale is subjective and prone to interobserver variability. Therefore, objective methods of evaluating the anterior visual pathway to reliably diagnose the morphological changes in IIH and guide therapeutical interventions are needed. ${ }^{21}$

In our study, the Frisén grade determined by direct fundus examination was significantly correlated with OCT parameters reflecting optic nerve head 
edema. While the Frisén grading scale for clinical papilledema ranges from grade 1 to 5 , the peripapillary RNFL thickness can range from $50 \mu \mathrm{m}$ to over $500 \mu \mathrm{m}$ giving it a much larger dynamic range to objectively evaluate for changes ${ }^{14,22,23}$. Average RNFL thickness was correlated with the clinical degree of papilledema, making it an accurate and reliable tool in detecting and monitoring optic nerve head edema, especially in patients with low-grade edema.

SS-OCT can play an important role in monitoring the disease process in $\mathrm{IIH}^{24}$. It has the advantage of providing a continuous measurement scale that can be understood even by an inexperienced observer and is less limited by cataract and pupil diameter than fundus examination. Thus far, there is no algorithm for optic disc edema interpretation, higher grades making it less reliable. However, our study proved that the RNFL measured with the SS-OCT 3-D algorithm may provide a sensitive and objective instrument to reliably assess and measure structural changes. Therefore, we advocate that OCT measurements of the optic nerve head and peripapillary retina can be a useful tool in the diagnosis and follow-up of papilledema in IIH.

\section{Compliance with Ethics Requirements:}

„The authors declare no conflict of interest regarding this article"

"The authors declare that all the procedures and experiments of this study respect the ethical standards in the Helsinki Declaration of 1975, as revised in 2008(5), as well as the national law. Informed consent was obtained from all the patients included in the study"

"No funding for this study"

\section{References}

1. Daniels AB, Liu GT, Volpe NJ, et al. Profiles of obesity, weight gain, and quality of life in idiopathic intracranial hypertension (pseudotumor cerebri). Am J Ophthalmol. 2007;143(4):635-641.

2. Chen J, Wall M. Epidemiology and risk factors for idiopathic intracranial hypertension. Int Ophthalmol Clin. 2014;54(1):1-11.

3. Szewka AJ, Bruce BB, Newman NJ, Biousse V. Idiopathic intracranial hypertension: relation between obesity and visual outcomes. J. Neuroophthalmol. 2013;33(1):4-8.

4. Markey KA, Mollan SP, Jensen RH, Sinclair AJ Understanding idiopathic intracranial hypertension: mechanisms, management, and future directions. Lancet Neurol. 2016;15(1):78-91.

5. Friedman DI, Liu GT, Digre KB. Revised diagnostic criteria for the pseudotumor cerebri syndrome in adults and children. Neurology. 2013;81:1159-1165.

6. Chen JJ, Thurtell MJ, Longmuir RA, et al. Causes and prognosis of visual acuity loss at the time of initial presentation in idiopathic intracranial hypertension. Invest Ophthalmol Vis Sci. 2015;56(6):3850-3859.

7. Wall M, Kupersmith MJ, Kieburtz KD, et al. The idiopathic intracranial hypertension treatment trial clinical profile at baseline. JAMA Neurol. 2014;71(6):693-701.

8. Wright BL, Lai JT, Sinclair AJ. Cerebrospinal fluid and lumbar puncture: a practical review. J Neurol. 2012;259:1530-45.

9. Merticariu CI, Balta F, Merticariu M, et al. Idiopathic intracranial hypertension and associated optic neuropathy in pediatric patients. J Transl Med Res. 2017;22(2):65-70.

10. Bruce BB. Nonmydriatic ocular fundus photography in the emergency department: how it can benefit neurologists. Semin Neuro.l 2015;35(5):491-5.

11. Ahuja S, Anand D, Dutta TK, Roopesh Kumar VR, Kar SS. Retinal nerve fiber layer thickness analysis in cases of papilledema using optical coherence tomography - A case control study. Clinical Neurology and Neurosurgery. 2015;136:95-99.

12. Rebolleda G, Muñoz-Negrete FJ. Follow-up of mild papilledema in idiopathic intracranial hypertension with optical coherence tomography. Invest Ophthalmol Vis Sci. 2009;50:5197-5200.

13. Wang XY, Huynh SC, Burlutsky G, et al. Reproducibility of and effect of magnification on optical coherence tomography measurements in children. Am J Ophthalmol. 2007;143(3):484- 488.

14. Scott CJ, Kardon RH, Lee AG, Frisén L, Wall M. Diagnosis and grading of papilledema in patients with raised intracranial pressure using optical coherence tomography vs clinical expert assessment using a clinical staging scale. Arch Ophthalmol. 2010;128:705-711.

15. Auinger P, Durbin M, Feldon S, et al. OCT Sub-Study Committee for NORDIC Idiopathic Intracranial Hypertension Study Group, Baseline OCT measurements in the idiopathic intracranial hypertension treatment trial, part II: correlations and relationship to clinical features. Investigative Ophthalmology $\mathcal{E}$ Visual Science. 2014;55(12):8173-9.

16. Biousse V, Bruce BB, Newman NJ. Update on the pathophysiology and management of idiopathic intracranial hypertension. J Neurol Neurosurg Psychiatry. 2012;83:488.

17. Bruce BB, Biousse V, Newman NJ. Update on idiopathic intracranial hypertension. Am J Ophthalmol. 2011;152(2):163-9.

18. Carta A, Bertuzzi F, Cologno D, et al. Idiopathic intracranial hypertension (pseudotumor cerebri): descriptive epidemiology, clinical features, and visual outcome in Parma, Italy, 1990 to 1999. Eur J Ophthalmol. 2004;14:48-54.

19. Asensio-Sánchez VM, Merino-Angulo J, Martínez Calvo S, et al. Epidemiology of pseudotumor cerebri. Arch Soc Esp Oftalmol. 2007;82:219-221.

20. Merticariu CI, Balta F, Merticariu M, et al. Optic neuropathy in idiopathic intracranial hypertension. J Transl Med Res. 2017;22(1):27-33

21. Chen J, Costello F. The role of optical coherence tomography in neuro-ophthalmology. Annals of Eye Science. 2018;3(6).

22. Sinclair AJ, Burdon MA, Nightingale PG, et al. Rating papilledema: an evaluation of the Frisen classification in idiopathic intracranial hypertension. J Neurol. 2012;259:1406-12.

23. Kardon R. Optical coherence tomography in papilledema: what am I missing? J Neuroophthalmol. 2014;34:S10-7.

24. Chen JJ, Trobe JD. Optical coherence tomography should be used routinely to monitor patients with idiopathic intracranial hypertension. J Neuroophthalmol. 2016;36:453-9. 